\title{
Seasonal thaw settlement at drained thermokarst lake basins, Arctic
}

\section{Alaska}

\author{
L. Liu ${ }^{1, *}$, K. Schaefer ${ }^{2}$, A. Gusmeroli ${ }^{3}$, G. Grosse ${ }^{4, * *}$, B. M. Jones ${ }^{5}$, T. Zhang ${ }^{2,6}$, A. D. Parsekian ${ }^{1, * * *}$, and \\ H. A. Zebker ${ }^{1}$ \\ ${ }^{1}$ Department of Geophysics, Stanford University, California, USA \\ ${ }^{2}$ National Snow and Ice Data Center, Cooperative Institute for Research in Environmental Sciences, \\ University of Colorado at Boulder, Colorado, USA \\ ${ }^{3}$ International Arctic Research Center, University of Alaska Fairbanks, Alaska, USA \\ ${ }^{4}$ Geophysical Institute, University of Alaska Fairbanks, Alaska, USA \\ ${ }^{5}$ Alaska Science Center, US Geological Survey, Anchorage, Alaska, USA \\ ${ }^{6}$ Ministry of Education Key Laboratory of West China's Environmental System, Lanzhou University, China \\ *now at: Earth System Science Programme, Faculty of Science, The Chinese University of Hong Kong, Hong Kong, China \\ *** now at: Alfred Wegener Institute Helmholtz Centre for Polar and Marine Research, Potsdam, Germany \\ **** now at: Department of Geology and Geophysics, University of Wyoming, Laramie, Wyoming, USA
}

Correspondence to: L. Liu (liulin@ cuhk.edu.hk)

Received: 19 November 2013 - Published in The Cryosphere Discuss.: 6 December 2013

Revised: 13 March 2014 - Accepted: 14 March 2014 - Published: 5 May 2014

\begin{abstract}
Drained thermokarst lake basins (DTLBs) are ubiquitous landforms on Arctic tundra lowland. Their dynamic states are seldom investigated, despite their importance for landscape stability, hydrology, nutrient fluxes, and carbon cycling. Here we report results based on highresolution Interferometric Synthetic Aperture Radar (InSAR) measurements using space-borne data for a study area located on the North Slope of Alaska near Prudhoe Bay, where we focus on the seasonal thaw settlement within DTLBs, averaged between 2006 and 2010. The majority (14) of the 18 DTLBs in the study area exhibited seasonal thaw settlement of 3-4 cm. However, four of the DTLBs examined exceeded $4 \mathrm{~cm}$ of thaw settlement, with one basin experiencing up to $12 \mathrm{~cm}$. Combining the InSAR observations with the in situ active layer thickness measured using ground penetrating radar and mechanical probing, we calculated thaw strain, an index of thaw settlement strength along a transect across the basin that underwent large thaw settlement. We found thaw strains of $10-35 \%$ at the basin center, suggesting the seasonal melting of ground ice as a possible mechanism for the large settlement. These findings emphasize the dynamic nature of permafrost landforms, demonstrate the capability of the InSAR technique to remotely monitor surface
\end{abstract}

deformation of individual DTLBs, and illustrate the combination of ground-based and remote sensing observations to estimate thaw strain. Our study highlights the need for better description of the spatial heterogeneity of landscape-scale processes for regional assessment of surface dynamics on Arctic coastal lowlands.

\section{Introduction}

Thermokarst lakes (or thaw lakes) are ubiquitous and dynamic landscape features on Arctic tundra lowlands (Sellman et al., 1975; Mackay, 1988; Frohn et al., 2005; Hinkel et al., 2005; Grosse et al., 2013). These lakes form as icerich permafrost thaws. They grow laterally and deepen, often coalescing with other lakes (Hopkins, 1949; Jorgenson and Shur, 2007). Many thermokarst lakes also drain, leaving depressed wetland basins known as drained thermokarst lake basins (DTLBs) (Mackay, 1988; Hinkel et al., 2007; Marsh et al., 2009). Taken together, thermokarst lakes and DTLBs cover $50-75 \%$ of the land surface in extensive Arctic lowland regions with ice-rich permafrost (Grosse et al., 2013). 
Most previous DTLB studies focus on either long-term evolution (e.g., Hinkel et al., 2003; Jorgenson and Shur, 2007; Regmi et al., 2012) or abrupt drainage events (e.g., Mackay, 1988). One exception is a series of field-based studies on Lake Illisarvik in Canada, which was artificially drained in 1978 (Mackay, 1997; Mackay and Burn et al., 2002). Mackay and Burn (2002) reported their $20 \mathrm{yr}$-long leveling survey results: during the first decade following the lake drainage, the basin surface underwent $\sim 10 \mathrm{~cm}$ of seasonal uplift (frost heave) and subsidence (thaw settlement); the magnitude of seasonal deformation dropped to $\sim 3 \mathrm{~cm}$ during the second decade.

In areas underlain by permafrost, seasonal frost heave and thaw settlement occur because of the seasonal phase change between ice and water as the active layer freezes and thaws. Specifically, active layer ice forms by three major mechanisms: (1) freezing and $9 \%$ volume expansion of soil water in pore space; (2) segregational heave due to upward water migration through the frozen fringe to form discrete layers or lenses, defined as segregated ice; and (3) water intrusion under pressure. Seasonal freezing and melting of pore ice results in a typical surface deformation of $1-4 \mathrm{~cm}$ on Arctic lowlands (Little et al., 2003; Liu et al., 2010; Burn, 1990; Nixon et al., 2003). Seasonal formation and melting of segregated and intrusive ice could induce larger surface deformation. For instance, maximum seasonal deformation of 10 $30 \mathrm{~cm}$ has been observed in field studies (Burn, 1990; Nixon et al., 2003).

Recent advances in remote sensing techniques offer a viable alternative to field-based measurements to monitor thaw settlement in remote locations and across larger regions. Interferometric Synthetic Aperture Radar (InSAR) is widely used to map surface deformation in various settings and has been recently applied to detect freeze/thaw-related vertical motion in permafrost lowlands (e.g., Liu et al., 2010; Short et al., 2011). These studies took advantage of the spatial coverage of space-borne data for regional surveys over areas of about $100 \mathrm{~km}$ by $100 \mathrm{~km}$.

Our primary objective in this study is to use highresolution InSAR data $(\sim 10 \mathrm{~m})$ to map and quantify seasonal thaw settlement at individual DTLBs in Arctic Alaska. In previous regional mapping efforts (e.g., Liu et al., 2010), these small landscape components have been ignored. Here we investigate the dynamic states of DTLBs, which are important for their impacts in geomorphology, surface hydrologic conditions, ground thermal, and soil biogeochemical conditions (Billings and Peterson, 1980; Yoshikawa and Hinzman, 2003; Schuur et al., 2007; Jones et al., 2012). Moreover, surface deformation in DTLBs can potentially affect carbon exchange and stability of the permafrost carbon pool (Hinkel et al., 2003).

Because the absolute magnitude of thaw settlement depends on the total water volume in the active layer and thus increases with active layer thickness (ALT) in a firstorder approximation, we use thaw strain, defined as the ra- tio between the thaw settlement and the difference between ALT and thaw settlement, as an index to quantify the relative strength of settlement. We conducted ground-based ALT measurements using probing and ground penetrating radar (GPR) at one DTLB that experienced strong seasonal settlement. Our secondary objective is to demonstrate the combination of satellite remote sensing and ground-based measurements to better quantify surface dynamics and to infer near-surface ground ice content.

\section{Study area and methods}

\subsection{Site description}

We studied a $20 \mathrm{~km}$ by $20 \mathrm{~km}$ area near Prudhoe Bay, on the Arctic coastal plain in northern Alaska. This region is underlain by $300-600 \mathrm{~m}$ thick permafrost with the upper $2-10 \mathrm{~m}$ containing large amounts of excess ground ice (Brown and Sellmann, 1973). ALT in the area varies from 30 to $80 \mathrm{~cm}$ (Nelson et al., 1997; Hinkel and Nelson, 2003; Walker et al., 2004; Streletskiy et al., 2008; Liu et al., 2012). The seasonal thaw settlement in this region varies between 1 and $4 \mathrm{~cm}$ based on survey-grade differential Global Positioning System (GPS) (Little et al., 2003) and $100 \mathrm{~m}$-resolution InSAR measurements (Liu et al., 2010). DTLBs are a dominant component of the surface landforms in this region and the formation and drainage of lakes is an important landscape change mechanism (Updike and Howland, 1979; Walker et al., 1985).

We chose this study area following the discovery of very strong seasonal settlements $(12 \mathrm{~cm}$, four times what was observed in the surrounding tundra) in one basin centered at $70^{\circ} 8^{\prime} 20^{\prime \prime} \mathrm{N}, 148^{\circ} 38^{\prime} 58^{\prime \prime} \mathrm{W}$. We informally named this DTLB as SAC basin after the institutions that the authors are affiliated with: Stanford, Alaska, and Colorado. We visited SAC basin in late summer of 2012 to examine the site and measured ALT.

SAC basin has a diameter of $\sim 800 \mathrm{~m}$ with a small residual pond on the east side connected to a thermokarst lake to the north through a narrow drainage channel (Fig. 1). The basin is flat with a peak-to-peak variation of only $0.6 \mathrm{~m}$ within the perimeter (Fig. 1b). By contrast, outside the DTLB is a typical tundra landscape with extensive ice-wedge polygon networks. An analysis of historic aerial photos indicates the lake drained before 1949 (photos provided by courtesy of the Alaska Satellite Facility GeoData Center, University of Alaska Fairbanks; not shown). Our field investigation found organic-rich, coarse gravelly and sandy soil along the basin margins with peat and silt in the central area. This spatial pattern is typical of DTLBs and is a result of sediment redistribution during the expansion stage of thermokarst lake development (Murton, 1996; Jorgenson and Shur, 2007). 


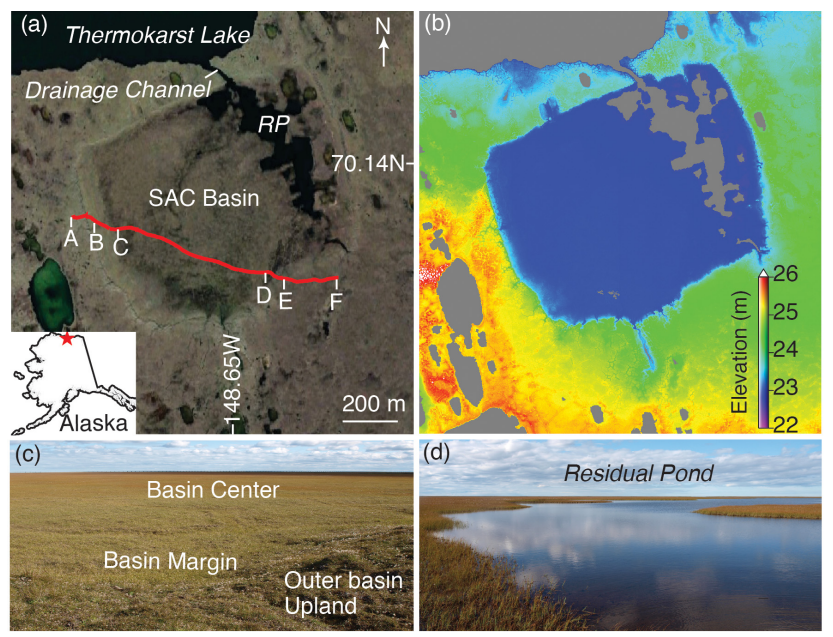

Fig. 1. (a) Google Earth ${ }^{\odot}$ image of SAC basin with the inset showing its location on the Alaskan North Slope near Prudhoe Bay. The red line ("A" to "F") shows the ground penetrating radar (GPR) transect across the basin and "RP" refers to the residual pond. (b) Elevation map with standing water bodies masked out in gray (source: Paine et al., 2013). (c) A photo of the basin center taken from point "A" looking east. (d) A photo of the residual pond.

\subsection{InSAR analysis}

By differencing radar phases of two SAR images acquired at different times, the InSAR technique produces an interferogram that maps ground surface deformation occurring during the two acquisitions in the line-of-sight (LOS) direction. We applied InSAR processing using a motion-compensation strategy (Zebker et al., 2010) to the Phased Array type Lband Synthetic Aperture Radar (PALSAR) data acquired by the Advanced Land Observing Satellite (ALOS). Using accurate satellite orbit information, this new processing strategy simplifies image co-registration and improves accuracy of InSAR measurements from conventional methods. We used two ascending PALSAR paths (250 and 251) and produced 33 interferograms between 2006 and 2010, which are shown in Fig. 2. These two interferogram networks of redundant measurements were used to reduce errors and to estimate the seasonal vertical deformation (Sect. 2.3). The $y$ axes of the Fig. 2 plots represent the perpendicular baseline of each interferogram, which is defined as the geometric separation of satellite positions at two acquisitions perpendicular to the LOS direction. Most of the interferograms we selected have perpendicular baselines shorter than $2000 \mathrm{~m}$ so that the InSAR geometric decorrelation problem is reduced (Zebker and Villasenor, 1992).

We also used a LiDAR DEM to remove the topographic contribution to the interferograms. This DEM has a fine spatial posting of $1 \mathrm{~m}$ and a vertical accuracy of $0.1 \mathrm{~m}$ (Paine et al., 2013). We downsampled the DEM to $10 \mathrm{~m}$ to match the interferogram posting. Following Liu et al. (2010), we used
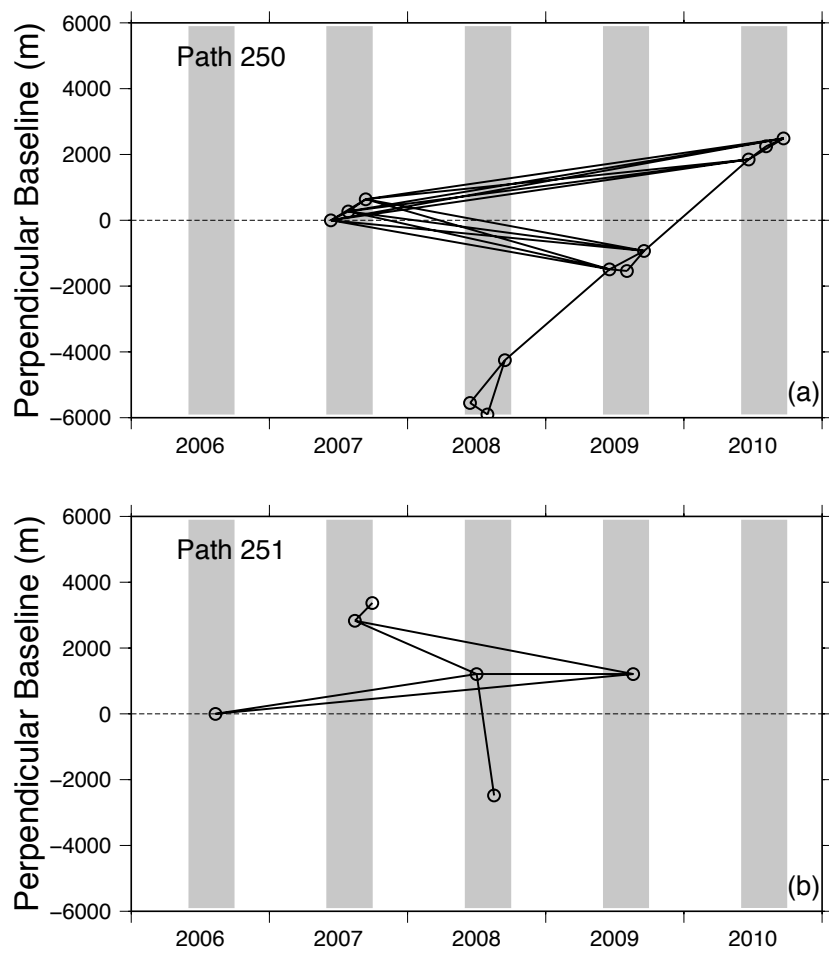

Fig. 2. Interferogram networks produced in this study using ALOS PALSAR data from two paths. Circles represent PALSAR acquisitions. Lines represent interferograms with sufficiently high coherence over SAC basin and vertical gray bars represent the thaw season (June to September). Perpendicular baseline values are referenced to 13 June 2007 and 12 August 2006 for Paths 250 and 251, respectively.

a river floodplain point $\left(70^{\circ} 4^{\prime} 40^{\prime \prime} \mathrm{N}, 148^{\circ} 32^{\prime} 15^{\prime \prime} \mathrm{W}\right)$ as a reference because the presence of coarse gravel results in a stable surface with little thaw settlement (Pullman et al., 2007). We also assumed the surface deformation in the study area is purely vertical and converted the InSAR-measured LOS deformation to the vertical direction. This is a valid assumption within the low lying, flat and homogeneous basin. In theory, lateral motions may occur on polygonal terrains due to thermal contraction and expansion; however, the reported lateral motions are small (less than $1 \mathrm{~cm} \mathrm{yr}^{-1}$ ) and confined in local scales across individual ice wedges (Mackay, 2000; Mackay and Burn, 2002).

In this study we only used SAR images acquired during thaw seasons to avoid severe phase decorrelation and artifacts due to snow cover. We also ruled out the possibility of detecting water level change instead of the basin elevation change. The basin is possibly flooded during snowmelt in early thaw season. However, InSAR detection of a flooded water body requires double-bounce backscattering that occurs at the interface between water surface and woody trunks/stems. This seldom occurs over tundra wetlands where surface vegetation are randomly distributed grasses/sedges. Double-bounce backscattering also results in 
strong SAR image amplitude and InSAR coherence, neither of which was observed in the interferograms over SAC basin.

\subsection{Estimation of thaw settlement}

Because individual interferograms are contaminated by errors due to atmospheric artifacts and decorrelation, we used all 33 interferograms and a time series model to invert for the multi-year average seasonal thaw settlement over 20062010. Here we briefly summarize the inversion method that has been described in detail by Liu et al. (2012). We modeled the InSAR-measured ground vertical deformation as a summation of a linear trend during 2006-2010 and the seasonal subsidence during thaw months as a linear function of the square root of the accumulated degree days of thaw (ADDT). We included the linear trend component for completeness, although we expected the trend was small. One difference from Liu et al. (2012) is that we excluded the topographic error term in our model because the LiDAR DEM has a high accuracy. Mathematically, InSAR-observed subsidence $(D)$ between two thaw-season dates $\left(t_{1}\right.$ and $\left.t_{2}\right)$, can be expressed as

$D=R\left(t_{2}-t_{1}\right)+E\left(\sqrt{A_{2}}-\sqrt{A_{1}}\right)+\varepsilon_{\mathrm{InSAR}}$,

where $R$ is the long-term subsidence rate, $E$ is the seasonal coefficient, $A$ is the ADDT with the subscripts corresponding to the two dates, and $\varepsilon_{\text {InSAR }}$ is InSAR measurement errors that we assume are random. We used the air temperature records at the Deadhorse Airport weather station (http: //www.ncdc.noaa.gov) to calculate ADDTs. We then fitted for both $R$ and $E$ from all interferograms using the leastsquares method and estimated their uncertainties. This inversion approach minimizes the contributions in the estimated seasonal subsidence due to temporal variations of soil moisture and tropospheric water vapor, because these two factors are not correlated with the ADDTs.

Despite excluding winter interferograms, we assumed that the ground vertical deformation is a full seasonal cycle in each year: that is, thaw-season subsidence and freeze-season uplift with the same magnitude. This is supported by the fact that our fitted linear trends during 2006-2010 have a magnitude $<0.5 \mathrm{~cm} \mathrm{yr}^{-1}$ that is smaller than the accuracy of PALSAR interferometry (Sandwell et al., 2008). In the remainder of this paper, we refer to the fitted maximum seasonal subsidence averaged between 2006 and 2010 as the InSARestimated thaw settlement and denote it as $\Delta Z$.

\subsection{GPR data analysis and ALT estimation}

GPR is a non-invasive geophysical method that uses electromagnetic signals to image the subsurface. GPR measures the travel time of radar waves transmitted into the ground and reflected at boundaries with different dielectric permittivity back to a receiver on the surface. Multiplying the one-way travel time to a reflecting interface by GPR wave speed gives the estimated depth of the reflections. Frozen and unfrozen sediments have a prominent dielectric contrast and result in clear, measurable radar reflections. For this reason, GPR is commonly used to map the spatial variability of thaw depth (e.g., Doolittle et al., 1990; Bradford et al., 2005; Brosten et al., 2006; Wollschläger et al., 2010; Hubbard et al., 2013).

We conducted a GPR survey to measure the thaw depth in SAC basin on 18 August 2012 along the red transect in Fig. 1a using a $500 \mathrm{MHz}$ PulseEkkoPro 1000 system. We also measured the thaw depth at ten locations along the profile using a metal probe to validate the GPR estimates and calibrate the radar wave speed. The GPR transect was acquired in common-offset mode, that is, the distance between transmitting and receiving antenna was constant during the entire survey. The GPR unit was set to collect a radar trace every $0.2 \mathrm{~s}$.

We processed the GPR data using standard routines (Neal, 2004) including removing the instrumental, low-frequency noise (dewow), $250-750 \mathrm{MHz}$ bandpass filtering, and an approximate spherical spreading correction by scaling the amplitude by the travel time. Additional data analysis details can be found in Gusmeroli and Grosse (2012). We estimated GPR wave speed within the subsurface by comparing radar travel times and probed thaw depth. GPR wave propagation speed within the active layer soils is $0.042 \mathrm{~m} \mathrm{~ns}^{-1}$, $0.052 \mathrm{mns}^{-1}$, and $0.042 \mathrm{mns}^{-1}$ outside the basin, in the sandy margin areas and inside the basin, respectively. Because we conducted GPR measurements near the end of the 2012 thaw season, the derived thaw depth is equivalent to the active layer thickness which we refer to as GPR ALT. Uncertainties in the GPR ALT are $\pm 6 \mathrm{~cm}$ based on calibration and validation with the probing measurements.

\subsection{Thaw strain}

Because the magnitude of thaw settlement typically increases with the thaw depth, we adopted thaw strain $(\varepsilon)$ as an index to quantify the relative strength of thaw settlement subsidence, which is defined as

$\varepsilon=\frac{\Delta Z}{H-\Delta Z}$,

where $\Delta Z$ is the thaw settlement and $H$ is the depth of thaw penetration (Pullman et al., 2007). In the context of examining the maximum seasonal deformation at $\mathrm{SAC}$ basin, $\Delta Z$ is the InSAR-measured thaw settlement and $H$ is the GPRestimated ALT. A similar and more commonly used index is frost strain, which is defined as the ratio of the frost heave over the depth of frost penetration minus the frost heave (Burn, 1990; French, 2007). The thaw and frost strains are equivalent if the thaw settlement and frost heave processes are reversible.

When active layer thawing occurs in a closed system, thaw settlement is only caused by the volume decrease associated with the melting of pore ice. Ignoring secondary mechanisms 
affecting thaw settlement (such as contraction of clay soils, consolidation of soil on thawing, surface erosion, changes in soil density, and unfrozen water content in the frozen soils), the thaw settlement is simply determined by the total volume of water in the active layer (Liu et al., 2012):

$\Delta Z=H \theta \frac{\rho_{\mathrm{w}}-\rho_{\mathrm{i}}}{\rho_{\mathrm{i}}}$,

where $\theta$ is the volumetric water content (VWC) of the active layer, $\rho_{\mathrm{w}}$ is the density of water, and $\rho_{\mathrm{i}}$ is the density of ice. Substituting Eq. (3) into Eq. (2) gives

$\varepsilon=\frac{\theta\left(\rho_{\mathrm{w}}-\rho_{\mathrm{i}}\right)}{\rho_{\mathrm{i}}-\theta\left(\rho_{\mathrm{w}}-\rho_{\mathrm{i}}\right)}$,

which is determined by $\theta$ and independent of $H$. According to Eq. (4), thaw strain in a closed system increases monotonically with $\theta$ and has an upper bound of $10 \%$ when $\theta=100 \%$ (i.e., pure water body).

\subsection{Estimation of volumetric water content from GPR wave speed}

Water content also largely determines the dielectric constant and thus the wave speed estimated from GPR measurements. In this subsection, we describe four methods of estimating ranges of $\theta$ (i.e., VWC) from the wave speeds, which we had determined using GPR and probing measurements (Sect. 2.4). We then used the $\theta$ values in Eq. (4) to predict thaw strains and compare with the observations.

Engstrom et al. (2005) developed the following sitespecific empirical model for the active layer over Barrow on the Arctic coast of Alaska:

$\theta=-2.5+2.508 \kappa-3.634 \times 10^{-2} \kappa^{2}+2.394 \times 10^{-4} \kappa^{3}$,

where $\kappa$ is the dielectric constant of the soil, which can be directly calculated from the GPR wave speed $v$ as

$\kappa=\left(\frac{c_{0}}{v}\right)^{2}$,

where $c_{0}$ is the speed of light in free space. We note that the study area of Engstrom et al. (2005) includes both DTLBs and upland terrains. Therefore, this empirical model is representative of the overall landscape in Barrow and may introduce some bias when applied to SAC basin.

We also considered a few other empirical relations for specific soil types. For instance, Parsekian et al. (2012) reported a linear regression relation for peat soils under nearsaturation conditions $(\theta>85 \%)$ :

$\theta_{\text {peat }}=4.4 \times 10^{-1}+7.3 \times 10^{-3} \kappa$.

For mineral soils, the following empirical equation developed by Topp et al. (1980) is widely used:

$$
\begin{aligned}
\theta_{\text {mineral }}= & -5.3 \times 10^{-2}+2.92 \times 10^{-2} \kappa \\
& -5.5 \times 10^{-4} \kappa^{2}+4.3 \times 10^{-6} \kappa^{3} .
\end{aligned}
$$

For saturated soils, the semi-empirical two-phase mixing equation based on the Complex Refractive Index Model (CRIM) is widely used to relate the dielectric constant to $\theta$ (e.g., Greaves et al., 1996):

$\sqrt{\kappa}=\theta \sqrt{\kappa_{\mathrm{w}}}+(1-\theta) \sqrt{\kappa_{\mathrm{g}}}$,

where $\kappa_{\mathrm{W}}$ and $\kappa_{\mathrm{g}}$ are the dielectric constants for pure water and solid matrix grains, respectively. Solving for $\theta$ gives

$\theta=\frac{\sqrt{\kappa}-\sqrt{\kappa_{\mathrm{g}}}}{\sqrt{\kappa_{\mathrm{w}}}-\sqrt{\kappa_{\mathrm{g}}}}$.

Equation (10) can be equivalently expressed as a function of GPR wave speeds in the mixed soil $(v)$, pure water $\left(v_{\mathrm{w}}\right)$, and solid matrix grains $\left(v_{\mathrm{g}}\right)$ as

$\theta=\frac{v_{\mathrm{w}}\left(v_{\mathrm{g}}-v\right)}{v\left(v_{\mathrm{g}}-v_{\mathrm{w}}\right)}$.

We used $\nu_{\mathrm{g}}=0.09 \mathrm{mns}^{-1}$ for dry organic matters and $0.15 \mathrm{~m} \mathrm{~ns}^{-1}$ for mineral grains, that is, quartz (Davis and Annan, 1989).

\section{Results}

\subsection{Seasonal thaw settlement}

All interferograms we produced show the same general pattern in SAC basin and its surroundings. In this subsection, we first show one interferogram as an example to illustrate strong settlement within SAC basin in a regional context including other DTLBs. We then present a detailed map of the 2006-2010 averaged thaw settlement at SAC basin.

The interferogram in Fig. 3 was formed using SAR images taken on 13 June 2007 and 13 September 2007, approximately at the start and end of the 2007 thaw season, respectively. Therefore, it represents the seasonal subsidence for a single year. Of the 18 DTLBs that show sufficient high InSAR coherence on this interferogram and have a size larger than 4 ha, 14 underwent similar subsidence as the surrounding tundra while four showed larger subsidence than the surrounding tundra. In particular, SAC basin experienced $12 \mathrm{~cm}$ of subsidence, or as much as $8-10 \mathrm{~cm}$ more than the surrounding area. SAC basin is clearly exceptional in terms of the magnitude of seasonal subsidence, but it is not unique.

The Trans-Alaska Pipeline is visible next to SAC basin as a linear and segmented feature. Along the pipeline, its interferometric phase pattern is doubled in the northern portion and triplicated near the white box due to multiple radar traveling paths to the elevated pipeline above ground. Such multiple-scattering signature is common on SAR images for man-made structures that are parallel to the ground surface (Zebker and Goldstein, 1986). A detailed investigation on the pipeline is outside the scope of this study. 


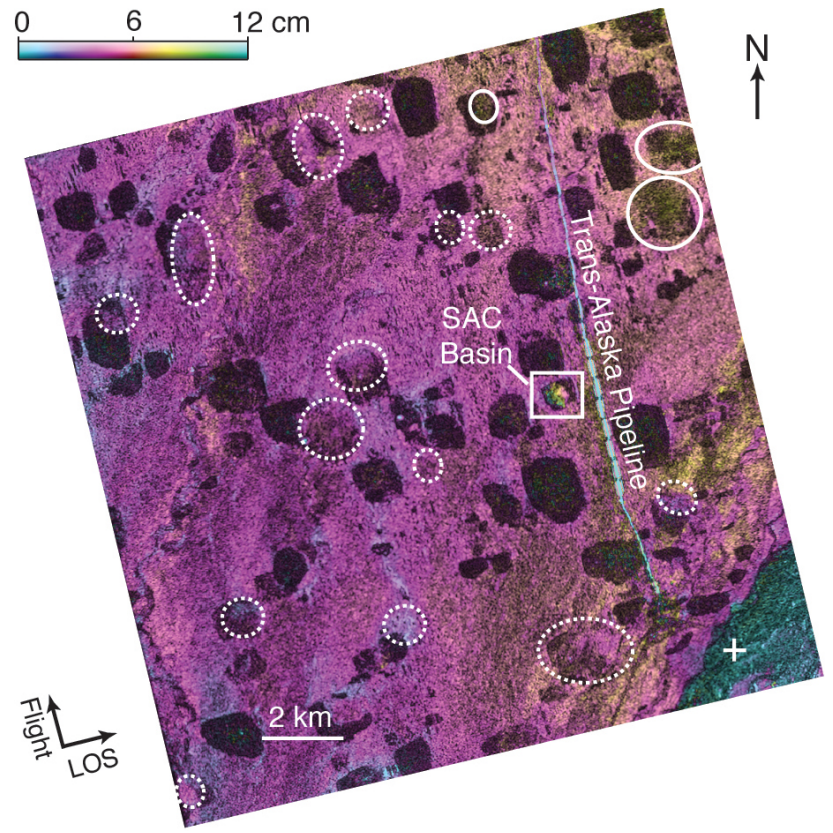

Fig. 3. An example interferogram showing seasonal thaw settlement of DTLBs and surroundings. Color indicates the surface thaw settlement between 13 June 2007 and 13 September 2007, projected in the satellite line-of-sight (LOS) direction, with the reference point located on the river floodplain (white cross). The white box marks SAC basin that underwent a strong settlement compared with the surrounding area. Solid circles outline DTLBs with stronger seasonal settlement than the surrounding tundra, and dashed circles outline DTLB with similar seasonal settlement as the surroundings. DTLBs smaller than 4 ha or having low interferometric coherence are not marked. The satellite flight and LOS directions are shown in the lower left.

Figure 4a shows the 2006-2010 average seasonal subsidence over SAC basin and its surrounding area, estimated using all 33 interferograms. Areas of low coherence, mostly over water bodies, are masked in gray. The tundra area outside SAC basin underwent an average seasonal thaw settlement of 3-4 cm. Consistent with the 2007 snapshot (Fig. 3), SAC Basin shows a large thaw settlement of up to $12 \mathrm{~cm}$ occurred over the western half of the basin bounded by the dry margins. Subsidence uncertainties range from 1 to $3 \mathrm{~cm}$ with a small spatial variability. Figure $4 \mathrm{~b}$ shows the relative uncertainties, defined as the ratios between the uncertainties and the absolute settlement. Over the area with large seasonal subsidence, the relative uncertainties are less than $20 \%$.

\subsection{Active layer water content and theoretical thaw strain}

We used GPR wave speeds of $0.042 \mathrm{mns}^{-1}$, representative for the entire active layer, to estimate VWC using the methods described in Sect. 2.6. We conducted similar calculations for the sandy basin margins, where GPR wave speed is
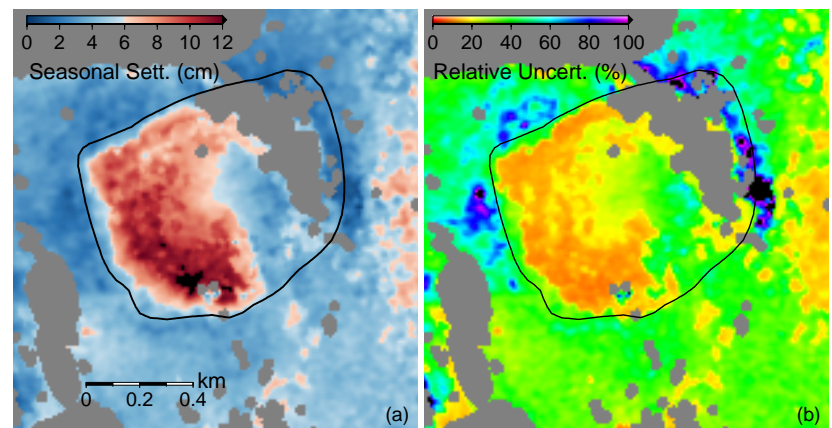

Fig. 4. (a) Average seasonal thaw settlement for 2006-2010 and (b) relative uncertainties in SAC basin and the surrounding tundra area. The black line shows the basin boundary, defined by the shoreline prior to drainage. Low coherence areas are masked out in gray.

$0.052 \mathrm{mns}^{-1}$. Table 1 lists the results. Given the uncertainty of the active layer soil composition and the spread results using different methods, we rounded off these estimates to represent the range of VWC as $60-80 \%$ for the basin center and outer basin, $45-55 \%$ for the sandy margins. The active layer at the basin center is fully saturated and consists of peat and silt, although the exact proportions are unknown. The VWC for saturated peat is about $90 \%$ (Price et al., 2005), so the VWC we estimated for the basin center is typical for soils with a large amount of organic material. The VWC of saturated pure mineral soil is about $45 \%$, depending on clay content (Clapp and Hornberger, 1978; Cosby et al., 1984), so the VWC we estimated for the sandy margins is typical of sandy soil with a small amount of organic material.

Based on these VWC estimates, we predicted thaw strains for saturated soils in a closed system using Eq. (4). The solid line in Fig. 5 denotes the full range of thaw strain with an upper limit of $10 \%$. The GPR-estimated VWCs of $60-80 \%$ at the basin center and the outer basin correspond to "theoretical" thaw strains ranging from $6 \%$ to $8 \%$, whereas VWCs of $45-55 \%$ along the basin margins correspond to thaw strains of $4-5 \%$, both for saturated soils in a closed system.

\subsection{Active layer thickness and estimated thaw strain}

In this subsection, we present the ALT, the seasonal subsidence, and the thaw strains along the GPR transect (Fig. 6). We divided the transect into areas outside the basin ("AB" and "EF"), the sandy margins ("BC" and "DE"), and the basin center ("CD").

Figure 7 shows a GPR radargram section that crosses these three types of units and demonstrates the prominent reflection boundary between unfrozen, wet active layer and frozen permafrost. Reflectors are obscured at the sandy margin section due to the lower contrast in physical properties between active layer and underlying permafrost along this segment of the transect. The weaker signal at depth could also be due to the strong reflections at low travel times, which reduce the 
Table 1. Volumetric water content (VWC, $\theta$ ) estimated based on the GPR wave speed $\left(0.042 \mathrm{mns}^{-1}\right)$ at the basin center and outer basin, and the GPR wave speed $\left(0.052 \mathrm{mns}^{-1}\right)$ at the sandy margins.

\begin{tabular}{|c|c|c|}
\hline Location & VWC $(\%)$ & Method \\
\hline \multirow{4}{*}{ 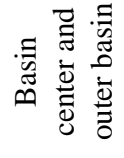 } & 63 & Empirical active layer, Eq. (5) \\
\hline & 81 & Empirical peat model, Eq. (7) \\
\hline & 68 & Two-phase mixing model for peat, Eq. (11), $v_{\mathrm{g}}=0.09 \mathrm{~m} \mathrm{~ns}^{-1}$ \\
\hline & 73 & Two-phase mixing model for silt, Eq. (11), $v_{\mathrm{g}}=0.15 \mathrm{~m} \mathrm{~ns}^{-1}$ \\
\hline \multirow{3}{*}{ 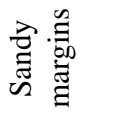 } & 50 & Empirical active layer, Eq. (5) \\
\hline & 47 & Empirical mineral model, Eq. (8) \\
\hline & 54 & Two-phase mixing model for sand, Eq. (11), $v_{\mathrm{g}}=0.15 \mathrm{mns}^{-1}$ \\
\hline
\end{tabular}

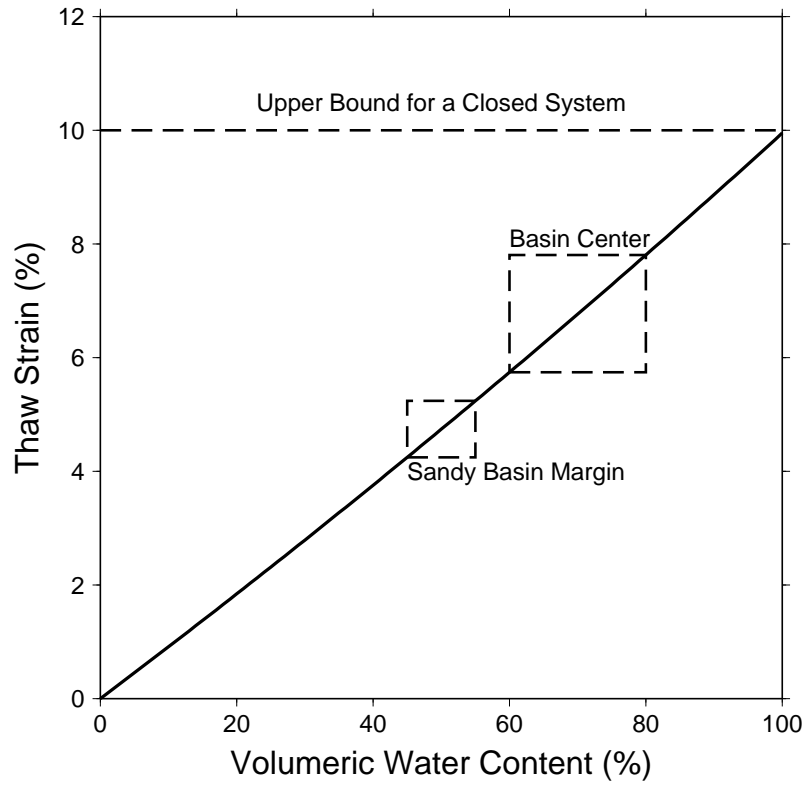

Fig. 5. Theoretical relation between the thaw strain and the volumetric water content when freezing and thawing of the soil occurs in a closed system. Thaw strain has an upper bound of $10 \%$. The two boxes outline the ranges of thaw strains and volumetric water contents for the sandy margins and the center of SAC basin, respectively.

signal intensity for reflection occurring in greater depths of the profile.

We calibrated the GPR ALT with the probing data, thus constraining a good match between these two measurements at all probing locations (Fig. 6a). ALT was about $0.4 \mathrm{~m}$ outside the basin, increasing to $0.7-1.3 \mathrm{~m}$ at the basin margins. At the basin center, ALT was relatively uniform with an average of $0.54 \mathrm{~m}$.

GPR combined with in situ probing provides a continuous profile of the ALT across multiple geological units at SAC basin. The ALT probe we used in the field has a maximum length of $1 \mathrm{~m}$, which did not reach the bottom of the active layer at the sandy margins. We overcame this thickness constraint and estimated the $>1 \mathrm{~m}$ ALT by using
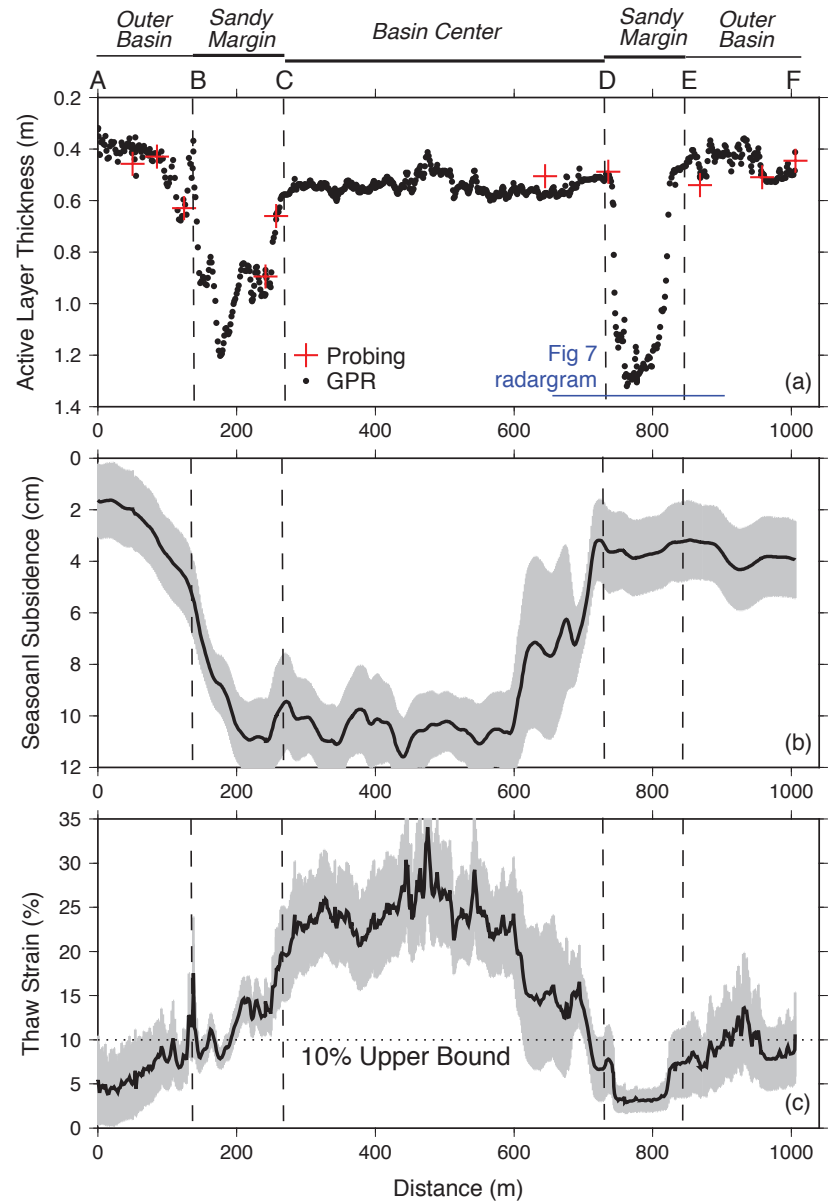

Fig. 6. (a) Active layer thickness along the Fig. 1a transect, estimated from probing (crosses) and GPR (dots). The uncertainties of the in situ and GPR ALT are $5 \mathrm{~cm}$ and $6 \mathrm{~cm}$, respectively, but are not shown. The blue horizontal bar marks the extent of the radargram shown in Fig. 7. (b) Profile of the seasonal subsidence based on InSAR measurements, with the uncertainties shown in gray. (c) Profile of the thaw strain, with the uncertainties shown in gray. The horizontal dotted line marks the upper bound for a closed system. 
GPR. Admittedly, in situ measurements using a long probe will be helpful to improve the interpretation of the observed reflections in the sandy margin area. The increased ALTs at the sandy margins from the surrounding typical tundra terrain are due to the high thermal conductivity and low latent heat (Osterkamp and Burn, 2002). Such characteristic pattern has been observed by in situ ALT measurements on the Arctic coastal plain of Alaska (e.g., Hinkel and Nelson, 2003; Shiklomanov et al., 2010).

The InSAR-measured seasonal thaw settlement along the transect was $2-4 \mathrm{~cm}$ outside the basin ("AB"), abruptly increasing to up to $12 \mathrm{~cm}$ at the basin center (subsidence bowl, "BD"), then decreasing to about $4 \mathrm{~cm}$ on the other side of the basin ("DF"). ALTs were similarly large at both margin sections ("BC" and "DE"), whereas subsidence was much larger along "BC" than "DE".

The thaw strains along the same profile show a similar but inverse spatial pattern as the thaw settlement (Fig. 6c). Outside the basin, thaw strains were $5-10 \%$ with a mean of $7 \%$. Along the sandy margin "DE", thaw strains were roughly constant at $3 \%$. At the entire basin center and part of the sandy margin "BC", thaw strains were systematically larger than $10 \%$.

\section{Discussion}

Comparisons between the calculated thaw strains and theoretical predictions based on VWC suggest the seasonal formation of excess ground ice. Outside the basin, the averaged thaw strain was $7 \%$, consistent with the theoretical range (6$8 \%$, given in Sect. 3.2). The averaged thaw strain along the margin "DE" was $3 \%$, slightly lower than the predicted 4$5 \%$ for saturated sandy soils in a closed system. Thaw strains at the basin center exceeded the $10 \%$ upper bound, suggesting the presence of ground ice whose equivalent VWC exceeds the soil pore volume in the active layer.

In wet conditions, development of segregated ice and intrusive ice can produce heave that exceeds what would be predicted from the volume expansion during the freezing of pore water, equivalently resulting in thaw or frost strains larger than $10 \%$. For instance, based on soil core analysis, Pullman et al. (2007) reported thaw strains that range from 20 to $35 \%$ for the top $1 \mathrm{~m}$ of ice-rich DTLB soils on the Beaufort coastal plain of Alaska, where SAC basin is located. Similarly, Burn (1990) reported frost strains of 20$60 \%$ for saturated, fine-grained lake-bottom sediments in the Mackenzie River delta.

Ground ice is abundant on the Arctic coastal plain (e.g., Kokelj and Burn, 2005; Kanevskiy et al., 2013). Specifically for SAC basin, ground ice in the active layer possibly bears the form of segregated ice and intrusive ice, resulting from two distinct processes. Following the lake drainage and refreezing of surface soils, ice enrichment occurs in the water-saturated, fine-grained active layer in the form of seg-

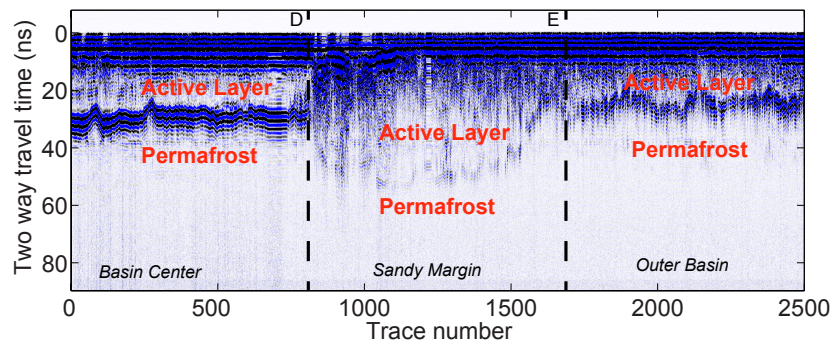

Fig. 7. A $500 \mathrm{MHz}$ dewowed radargram that crosses the three geological units of our study. The horizontal extent of this profile is marked in Fig 6, which is approximately $200 \mathrm{~m}$ and crosses markers "D" and "E".

regated ice as permafrost aggrades from below (Bockheim and Hinkel, 2012). On the other hand, SAC basin has a residual pond on its east side. During the winter when the pond freezes, pressure is built within the remaining liquid water. Extra pressure may inject the floodwater laterally along the base of the active layer and form ground ice, which could be a secondary ice-forming mechanism. We note that ground ice is also present in the surrounding tundra including the polygonal outer basin. Our thaw strain calculations suggest that its water equivalent is confined within the soil pore space, in contrast with the basin center where extensive ground ice exceeds the pore space.

Our estimated thaw strains are much larger in "BC" than in "DE", although both sections are at sandy margins. We speculate that this contrast may reflect the heterogeneous distribution of ground ice, which is more likely to accumulate in "BC" than in "DE". However, the exact mechanisms of such difference are related to soil composition and texture, which are unknown and will be investigated in future studies.

We did not identify massive ground ice in our GPR data. We conducted GPR survey at the end of the thaw season, aiming to measure ALT. The reflection at the freeze-thaw interface is so strong that we cannot image any structures beneath the permafrost table (Fig. 7). GPR surveys in frozen season, however, have great potential for detection of excess ice bodies as their distinct geometry results in specific reflection patterns. Moorman et al. (2003) gave examples of these reflection patterns, which vary according to the size of the ice bodies.

All the VWC and thaw strain models used in this study assume fully saturated soils. This assumption applies to most places in our study area, but may be invalid at certain places, for example, some areas at the outer basin where the elevation is higher. By assuming full saturation at these places, we would have overestimated the theoretical thaw strain using Eq. (4) and overestimated VWC using GPR wave speed, which are difficult to quantify without in situ observation of saturation fraction. Nonetheless, the estimated subsidence, ALT, as well as the thaw strains based on the previous two are all independent of the fully saturation assumption. 
Mapping and quantifying vertical motion at individual landscape components such as DTLBs described in this study is important for better describing regional patterns in surface deformation on Arctic coastal lowlands. These landscapes are characterized by a mosaic of extent lakes, DTLBs, and remnant topography (Frohn et al., 2005; Hinkel et al., 2005; Grosse et al., 2013) that vary by ground-ice content and soil sediment grain size (Kanevskiy et al., 2013). These differences result in highly variable seasonal deformation that becomes averaged across the landscape when using coarser resolution imagery employed in previous studies (e.g., Liu et al., 2010). The maximum observed motion of $8-12 \mathrm{~cm}$ that was observed in SAC basin and the other DTLBs that experienced greater than $4 \mathrm{~cm}$ of seasonal deformation highlight the importance of conducting high spatial resolution InSAR studies in these settings. It is likely that landscape components of various ages and hence ground ice content will respond differently to climate change. Therefore, the ability to detect this with InSAR at the level of individual landscape components is important for documenting dynamics due to thermokarst and landscape evolution on Arctic coastal lowlands. Given the large amount and extensive coverage of DTLBs on Arctic lowlands and the availability of SAR data acquired by multiple satellites, it would be valuable to conduct a regional-scale InSAR analysis to identify basins that are experiencing similar seasonal deformation as SAC basin.

We expect other DTLBs on the Arctic coastal lowlands will show spatial variations in surface deformation similar to SAC basin, reflecting differences in active layer water content. Investigating the mechanism(s) that drive these spatial variations requires detailed ground-based measurements of active layer thickness, saturation fraction, soil porosity, ground ice content, and other physical characteristics. Remote sensing InSAR maps are a useful tool to help plan and conduct such field measurements.

\section{Conclusions}

We have applied the InSAR technique to ALOS PALSAR data to examine the surface dynamics of DTLBs in northern Alaska. Most of the DTLBs in our study area underwent seasonal thaw settlement of $3-4 \mathrm{~cm}$. We have also found a prominent seasonal thaw settlement at one particular DTLB, SAC basin, every year from 2006 to 2010 with a maximum of $12 \mathrm{~cm}$ with less than $20 \%$ of relative uncertainty. This is significantly larger than the thaw settlement observed at the surrounding tundra area and other nearby DTLBs.

Combining the InSAR thaw settlement and the GPR ALT measurements at SAC basin, we calculated thaw strain and used it as an index of settlement strength. The averaged thaw strain was $7 \%$ and $3 \%$ outside the basin and along the sandy basin margins, respectively, quantitatively consistent with the theoretical values for freeze and thaw of saturated or nearsaturated active layer soils. Thaw strains at the basin center were systematically larger than $10 \%$ with a maximum value of $35 \%$, indicating the presence of excess ground ice the active layer.

Previous InSAR studies overlooked deformation at individual DTLBs. If the observations reported in this study are related to a common process over a broad region, such large seasonal thaw settlement has significant implications for permafrost hydrology and landscape dynamics. Capturing spatial heterogeneity of landscape-scale processes as suggested in this study is important for better describing regional patterns in surface deformation in Arctic coastal lowlands.

Acknowledgements. We thank three anonymous reviewers and W. Zhao for their constructive comments. The ALOS PALSAR data are copyrighted by the Japan Aerospace Exploration Agency and provided by the Alaska Satellite Facility, University of Alaska Fairbanks. L. Liu was supported by the George Thompson Postdoctoral Fellowship from the Department of Geophysics, Stanford University and the US National Science Foundation (NSF) grant ARC-1204013. K. Schaefer and T. Zhang were in part supported by the US National Aeronautics and Space Administration (NASA) NNX10AR63G, the US National Oceanic and Atmospheric Administration NA09OAR4310063, and the NSF ARC-0901962. A. Gusmeroli was supported by the Alaska Climate Science Center, funded by cooperative agreement number G10AC00588 from the US Geological Survey. G. Grosse was supported by NASA NNX11AH20G and NSF ARC-1107481. B. M. Jones was supported by the US Geological Survey, Alaska Science Center and the Land Change Science program. We thank J. Paine, A. Hosford Scheirer, E. Duncan and K. Duncan (Great Bear Petroleum) for providing the LiDAR DEM. We thank E. Pettit, J. Munk, M. Sturm, and C. Jones for providing field instruments. Any use of trade, product, or firm names is for descriptive purposes only and does not imply endorsement by the US Government.

Edited by: J. Boike

\section{References}

Billings, W. and Peterson, K.: Vegetational change and ice-wedge polygons through the thaw-lake cycle in Arctic Alaska, Arctic Alpine Res., 12, 413-432, 1980.

Bockheim, J. G. and Hinkel, K. M.: Accumulation of excess ground ice in an age sequence of drained thermokarst lake basins, Arctic Alaska, Permafrost Periglac., 23, 231-236, doi:10.1002/ppp.1745, 2012.

Bradford, J. H., McNamara, J. P., Bowden, W., and Gooseff, M. N.: Measuring thaw depth beneath peat-lined arctic streams using ground-penetrating radar, Hydrol. Process., 19, 2689-2699, 2005.

Brosten, T. R., Bradford, J. H., McNamara, J. P., Zarnetske, J. P., Gooseff, M. N., and Bowden, W. B.: Profiles of temporal thaw depths beneath two arctic stream types using ground-penetrating radar, Permafrost Periglac., 17, 341-355, 2006.

Brown, J. and Sellmann, P. V.: Permafrost and coastal plain history of arctic Alaska, in: Alaskan Arctic Tundra, edited by: Brit- 
ton, M. E., no. 25 in Arctic Institute of North America, Technical Paper, 31-47, 1973.

Burn, C.: Frost heave in lake-bottom sediments, Mackenzie Delta, Northwest Territories, in: 5th Canadian Permafrost Conference, Université Laval, Quebéc, 6-8 June 1990, 54, 103-109, 1990.

Clapp, R. B. and Hornberger, G. M.: Empirical equations for some soil hydraulic properties, Water Resour. Res., 14, 601-604, 1978.

Cosby, B., Hornberger, G., Clapp, R., and Ginn, T.: A statistical exploration of the relationships of soil moisture characteristics to the physical properties of soils, Water Resour. Res., 20, 682-690, 1984.

Davis, J. and Annan, A.: Ground-penetrating radar for highresolution mapping of soil and rock stratigraphy, Geophys. Prospect., 37, 531-551, 1989.

Doolittle, J., Hardisky, M., and Gross, M.: A ground-penetrating radar study of active layer thicknesses in areas of moist sedge and wet sedge tundra near Bethel, Alaska, USA, Arctic Alpine Res., 22, 175-182, 1990.

Engstrom, R., Hope, A., Kwon, H., Stow, D., and Zamolodchikov, D.: Spatial distribution of near surface soil moisture and its relationship to microtopography in the Alaskan Arctic Coastal Plain, Nord. Hydrol., 36, 219-234, 2005.

French, H. M.: The Periglacial Environment, John Wiley \& Sons, Ltd., New York, 2007.

Frohn, R., Hinkel, K., and Eisner, W.: Satellite remote sensing classification of thaw lakes and drained thaw lake basins on the North Slope of Alaska, Remote Sens. Environ., 97, 116-126, 2005.

Greaves, R. J., Lesmes, D. P., Lee, J. M., and Toksöz, M. N.: Velocity variations and water content estimated from multi-offset, ground-penetrating radar, Geophysics, 61, 683-695, 1996.

Grosse, G., Jones, B., and Arp, C.: Thermokarst lakes, drainage, and drained basins, in: Treatise on Geomorphology, edited by: Shroder, J. G. R. and Harbor, J., Elsevier Academic Press, San Diego, California, 81-29, 2013.

Gusmeroli, A. and Grosse, G.: Ground penetrating radar detection of subsnow slush on ice-covered lakes in interior Alaska, The Cryosphere, 6, 1435-1443, doi:10.5194/tc-6-1435-2012, 2012.

Hinkel, K. M. and Nelson, F.: Spatial and temporal patterns of active layer thickness at Circumpolar Active Layer Monitoring (CALM) sites in northern Alaska, 1995-2000, J. Geophys. Res., 108, 8168, doi:10.1029/2001JD000927, 2003.

Hinkel, K. M., Eisner, W., Bockheim, J., Nelson, F., Peterson, K., and Dai, X.: Spatial extent, age, and carbon stocks in drained thaw lake basins on the Barrow Peninsula, Alaska, Arct. Antarct. Alp. Res., 35, 291-300, 2003.

Hinkel, K. M., Frohn, R., Nelson, F., Eisner, W., and Beck, R.: Morphometric and spatial analysis of thaw lakes and drained thaw lake basins in the western Arctic Coastal Plain, Alaska, Permafrost Periglac., 16, 327-341, 2005.

Hinkel, K. M., Jones, B. M., Eisner, W. R., Cuomo, C. J., Beck, R. A., and Frohn, R.: Methods to assess natural and anthropogenic thaw lake drainage on the western Arctic coastal plain of northern Alaska, J. Geophys. Res., 112, F02S16, doi:10.1029/2006JF000584, 2007.

Hopkins, D. M.: Thaw lakes and thaw sinks in the Imuruk Lake Area, Seward Peninsula, Alaska, J. Geol., 57, 119-131, 1949.

Hubbard, S. S., Gangodagamage, C., Dafflon, B., Wainwright, H., Peterson, J., Gusmeroli, A., Ulrich, C., Wu, Y., Wilson, C., Rowland, J., Tweedie, C., and Wullschleger, S.: Quantifying and re- lating land-surface and subsurface variability in permafrost environments using LiDAR and surface geophysical datasets, Hydrogeol. J., 21, 149-169, 2013.

Jones, M. C., Grosse, G., Jones, B. M., and Walter Anthony, K.: Peat accumulation in drained thermokarst lake basins in continuous, ice-rich permafrost, northern Seward Peninsula, Alaska, J. Geophys. Res., 117, G00M07, doi:10.1029/2011JG001666, 2012.

Jorgenson, M. T. and Shur, Y.: Evolution of lakes and basins in northern Alaska and discussion of the thaw lake cycle, J. Geophys. Res., 112, F02S17, doi:10.1029/2006JF000531, 2007.

Kanevskiy, M., Shur, Y., Jorgenson, M., Ping, C.-L., Michaelson, G., Fortier, D., Stephani, E., Dillon, M., and Tumskoy, V.: Ground ice in the upper permafrost of the Beaufort Sea coast of Alaska, Cold Reg. Sci. Technol., 85, 56-70, 2013.

Kokelj, S. and Burn, C.: Near-surface ground ice in sediments of the Mackenzie Delta, Northwest Territories, Canada, Permafrost Periglac., 16, 291-303, 2005.

Little, J., Sandall, H., Walegur, M., and Nelson, F.: Application of Differential Global Positioning Systems to monitor frost heave and thaw settlement in tundra environments, Permafrost Periglac., 14, 349-357, doi:10.1002/ppp.466, 2003.

Liu, L., Zhang, T., and Wahr, J.: InSAR measurements of surface deformation over permafrost on the North Slope of Alaska, J. Geophys. Res., 115, F03023, doi:10.1029/2009JF001547, 2010.

Liu, L., Schaefer, K., Zhang, T., and Wahr, J.: Estimating 19922000 average active layer thickness on the Alaskan North Slope from remotely sensed surface subsidence, J. Geophys. Res., 117, F01005, doi:10.1029/2011JF002041, 2012.

Mackay, J. R.: Catastrophic lake drainage, Tuktoyaktuk Peninsula area, District of Mackenzie, Current Research, Part D, Geological Survey of Canada, Paper, 88, 83-90, 1988.

Mackay, J. R.: A full-scale field experiment (1978-1995) on the growth of permafrost by means of lake drainage, western Arctic coast: A discussion of the method and some results, Can. J. Earth Sci., 34, 17-33, 1997.

Mackay, J. R.: Thermally induced movements in ice-wedge polygons, western Arctic coast: a long-term study, Geogr. Phys. Quatern., 54, 41-68, 2000.

Mackay, J. R. and Burn, C. R.: The first 20 years (1978-1979 to 1998-1999) of active-layer development, Illisarvik experimental drained lake site, western Arctic coast, Canada, Can. J. Earth Sci., 39, 1657-1674, 2002.

Marsh, P., Russell, M., Pohl, S., Haywood, H., and Onclin, C.: Changes in thaw lake drainage in the Western Canadian Arctic from 1950 to 2000, Hydrol. Process., 23, 145-158, 2009.

Moorman, B., Robinson, S., and Burgess, M.: Imaging periglacial conditions with ground-penetrating radar, Permafrost Periglac., 14, 319-329, doi:10.1002/ppp.463, 2003.

Murton, J. B.: Thermokarst-lake-basin sediments, Tuktoyaktuk Coastlands, western arctic Canada, Sedimentology, 43, 737-760, 1996.

Neal, A.: Ground-penetrating radar and its use in sedimentology: principles, problems and progress, Earth-Sci. Rev., 66, 261-330, 2004.

Nelson, F. E., Shiklomanov, N. I., Mueller, G. R., Hinkel, K. M., Walker, D. A., and Bockheim, J. G.: Estimating active-layer thickness over a large region: Kuparuk river basin, Alaska, USA, Arctic Alpine Res., 29, 367-378, 1997. 
Nixon, M., Tarnocai, C., and Kutny, L.: Long-term active layer monitoring: Mackenzie Valley, northwest Canada, in: Proceedings of the 8th International Conference on Permafrost, 2, 821$826,2003$.

Osterkamp, T. E. and Burn, C. R.: Permafrost, in: Encyclopedia of Atmospheric Sciences, edited by: Holton, J. R., Pyle, J., and Curry, J. A., 1717-1729, Academic Press, New York, NY, 2002.

Paine, J. G., Andrews, J. R., Saylam, K., Tremblay, T. A., Averett, A. R., Caudle, T. L., Meyer, T., and Young, M. H.: Airborne lidar on the Alaskan North Slope: Wetlands mapping, lake volumes, and permafrost features, The Leading Edge, 32, 798805, 2013.

Parsekian, A. D., Slater, L., and Giménez, D.: Application of ground-penetrating radar to measure near-saturation soil water content in peat soils, Water Resour. Res., 48, W02533, doi:10.1029/2011WR011303, 2012.

Price, J. S., Cagampan, J., and Kellner, E.: Assessment of peat compressibility: is there an easy way?, Hydrol. Process., 19, 34693475, 2005.

Pullman, E. R., Jorgenson, M. T., and Shur, Y.: Thaw settlement in soils of the Arctic Coastal Plain, Alaska, Arct. Antarct. Alp. Res., 39, 468-476, 2007.

Regmi, P., Grosse, G., Jones, M. C., Jones, B. M., and Anthony, K. W.: Characterizing post-drainage succession in thermokarst lake basins on the Seward Peninsula, Alaska with TerraSAR-X backscatter and Landsat-based NDVI data, Remote Sens., 4, 3741-3765, 2012.

Sandwell, D. T., Myer, D., Mellors, R., Shimada, M., Brooks, B., and Foster, J.: Accuracy and resolution of ALOS interferometry: Vector deformation maps of the Father's Day intrusion at Kilauea, IEEE T. Geosci. Remote, 46, 3524-3534, 2008.

Schuur, E. A. G., Crummer, K., Vogel, J., and Mack, M.: Plant species composition and productivity following permafrost thaw and thermokarst in Alaskan tundra, Ecosystems, 10, 280-292, 2007.

Sellmann, P., Brown, J., Lewellen, R., McKim, H., and Merry, C.: The Classification and Geomorphic Implications of Thaw Lakes on the Arctic Coastal Plain, Alaska, Tech. Rep. 344, Cold Regions Res. and Eng. Lab., Hanover, NH, 1975.

Shiklomanov, N. I., Streletskiy, D. A., Nelson, F. E., Hollister, R. D., Romanovsky, V. E., Tweedie, C. E., Bockheim, J. G., and Brown, J.: Decadal variations of active-layer thickness in moisture-controlled landscapes, Barrow, Alaska, J. Geophys. Res., 115, G00I04, doi:10.1029/2009JG001248, 2010.
Short, N., Brisco, B., Couture, N., Pollard, W., Murnaghan, K., and Budkewitsch, P.: A comparison of TerraSAR-X, RADARSAT-2 and ALOS-PALSAR interferometry for monitoring permafrost environments, case study from Herschel Island, Canada, Remote Sens. Environ., 115, 3491-3506, 2011.

Streletskiy, D. A., Shiklomanov, N. I., Nelson, F. E., and Klene, A. E.: Long-term active and ground surface temperature trends: 13 years of observations at Alaskan CALM sites, in: Ninth International Conference on Permafrost, 29, 1727-1732, 2008.

Topp, G., Davis, J., and Annan, A. P.: Electromagnetic determination of soil water content: Measurements in coaxial transmission lines, Water Resour. Res., 16, 574-582, 1980.

Updike, R. and Howland, M.: Surficial geology and processes, Prudhoe Bay oil field, with Hydrologic implications, Tech. rep., Alaska Division of Geological and Geophysical Surveys Special Report, 1979.

Walker, D. A., Walker, M. D., Everett, K. R., and Webber, P.: Pingos of the Prudhoe Bay Region, Alaska, Arctic Alpine Res., 17, 321336, 1985.

Walker, D. A., Epstein, H. E., Gould, W. A., Kelley, A. M., Kade, A. N., Knudson, J. A., Krantz, W. B., Michaelson, G., Peterson, R. A., Ping, C.-L., Raynolds, M. K., Romanovsky, V. E., and Shur, Y.: Frost-boil ecosystems: complex interactions between landforms, soils, vegetation and climate, Permafrost Periglac., 15, 171-188, doi:10.1002/ppp.487, 2004.

Wollschläger, U., Gerhards, H., Yu, Q., and Roth, K.: Multi-channel ground-penetrating radar to explore spatial variations in thaw depth and moisture content in the active layer of a permafrost site, The Cryosphere, 4, 269-283, doi:10.5194/tc-4-269-2010, 2010.

Yoshikawa, K. and Hinzman, L. D.: Shrinking thermokarst ponds and groundwater dynamics in discontinuous permafrost near council, Alaska, Permafrost Periglac., 14, 151-160, 2003.

Zebker, H. A. and Goldstein, R. M.: Topographic mapping from interferometric synthetic aperture radar observations, J. Geophys. Res., 91, 4993-4999, 1986.

Zebker, H. A. and Villasenor, J.: Decorrelation in interferometric radar echoes, IEEE T. Geosci. Remote, 30, 950-959, 1992.

Zebker, H., Hensley, S., Shanker, P., and Wortham, C.: Geodetically Accurate InSAR Data Processor, IEEE T. Geosci. Remote, 48, 4309-4321, doi:10.1109/TGRS.2010.2051333, 2010. 


\section{Appendix A}

Table A1. Notation and constants.

\begin{tabular}{|c|c|}
\hline$D$ & Ground vertical deformation measured in individual InSAR interferograms (m) \\
\hline$R$ & Long-term subsidence rate $\left(\mathrm{m} \mathrm{yr}^{-1}\right)$ \\
\hline$t$ & Time $(y r)$ \\
\hline$E$ & Coefficient of seasonal subsidence $\left(\mathrm{m}^{\circ} \mathrm{C}^{-1 / 2}\right.$ days $\left.{ }^{-1 / 2}\right)$ \\
\hline$A$ & Accumulated degree days of thaw $\left({ }^{\circ} \mathrm{C}\right.$ days $)$ \\
\hline$\varepsilon_{\text {InSAR }}$ & Random errors in InSAR deformation measurements (m) \\
\hline$\theta$ & Volumetric water content (-) \\
\hline$\kappa$ & Dielectric constant of soil (-) \\
\hline$\kappa_{\mathrm{W}}$ & Dielectric constant of pure water (80) \\
\hline$\kappa_{\mathrm{g}}$ & Dielectric constant of solid matrix grains $(-)$ \\
\hline$v$ & GPR wave speed $\left(\mathrm{ms}^{-1} ; \mathrm{mns}^{-1}\right.$ is used in this study) \\
\hline$v_{\mathrm{w}}$ & GPR wave speed in fresh water $\left(0.033 \mathrm{mns}^{-1}\right)$ \\
\hline$v_{\mathrm{g}}$ & $\begin{array}{l}\text { GPR wave speed in solid matrix grains: } 0.09 \mathrm{mns}^{-1} \text { for dry organic matters, } \\
0.15 \mathrm{mns}^{-1} \text { for silt and sand (Davis and Annan, 1989) }\end{array}$ \\
\hline$c_{0}$ & The speed of light in free space $\left(2.9979 \times 10^{8} \mathrm{~ms}^{-1}\right)$ \\
\hline$\varepsilon$ & Thaw strain $(-)$ \\
\hline$\Delta Z$ & Thaw settlement ( $\mathrm{m} ; \mathrm{cm}$ is used in this study) \\
\hline$H$ & Depth of thaw penetration (m) \\
\hline$\rho_{\mathrm{W}}$ & Density of water $\left(1000 \mathrm{~kg} \mathrm{~m}^{-3}\right)$ \\
\hline$\rho_{\mathrm{i}}$ & Density of pure ice $\left(917 \mathrm{~kg} \mathrm{~m}^{-3}\right)$ \\
\hline
\end{tabular}

